\title{
Severity of illness influences the microcirculatory response to red blood cell transfusion in the critically ill: an observational cohort study
}

Lisa van Manen ${ }^{1,2^{*}} \mathbb{D}$, Jessica M. Deurvorst ${ }^{1}$, Maike E. van Hezel ${ }^{1,2}$, Margit Boshuizen ${ }^{1,2}$, Robin van Bruggen ${ }^{2 \dagger}$ and Nicole P. Juffermans ${ }^{1,3+}$

Keywords: Red blood cell transfusion, Anemia, Microcirculation, SOFA score

\section{Main text}

Critically ill patients frequently require red blood cell (RBC) transfusions. The aim of giving a RBC transfusion is to increase oxygen delivery to tissues in anemic patients. The oxygen delivering capacity depends not only on the hemoglobin $(\mathrm{Hb})$ level and oxygen saturation, but also on tissue perfusion. In current clinical practice, transfusion decisions are based on the $\mathrm{Hb}$ level only. However, baseline $\mathrm{Hb}$ level does not correlate with a positive effect of a RBC transfusion on tissue perfusion [1]. The effect of a RBC transfusion seems to depend on the baseline microcirculatory flow $[1,2]$. However, routine measurements of the microcirculatory flow in clinical practice are difficult, since microcirculatory flow evaluation requires experience and the analysis of the videos is time-consuming. We hypothesized that organ injury level of the patient influences the microcirculatory response of the recipient to $\mathrm{RBC}$ transfusion, rendering the Sequential Organ Failure Assessment (SOFA) score

\footnotetext{
* Correspondence: I.vanmanen@amsterdamumc.nl

${ }^{\dagger}$ Robin van Bruggen and Nicole P. Juffermans contributed equally to this work.

${ }^{1}$ Department of Intensive Care Medicine and Laboratory of Experimental Intensive Care and Anesthesiology, Amsterdam UMC, location AMC, University of Amsterdam, Meibergdreef 9, 1105 AZ Amsterdam, The Netherlands

${ }^{2}$ Department of Blood Cell Research, Sanquin research and Landsteiner Laboratory, University of Amsterdam, Amsterdam, The Netherlands Full list of author information is available at the end of the article
}

an easy bedside value which could aid in transfusion decision-making.

We performed sublingual Sidestream DarkField (SDF) imaging (Microscan, MicroVision Medical, Amsterdam, The Netherlands) within $1 \mathrm{~h}$ before and after transfusion of 1 leucodepleted RBC unit in 18 anemic non-bleeding critically ill patients on a tertiary intensive care. The study was ethically approved by the medical ethical committee of the Amsterdam University Medical Centre (NTR 6596; NL61833.018.17). Written informed consent was obtained from all participants or their legal representatives. Software AVA 3.2, MicroVision Medical, Amsterdam, The Netherlands, was used to analyze the videos and to calculate the "De Backer" score (including vessel density, proportion of perfused vessels (PPV) and perfused vessel density (PVD)) and the Microvascular Flow Index (MFI) [3]. Wilcoxon signed-rank test was used to compare paired data. Correlation coefficient between the delta of the SDF values (difference between before and after transfusion) and SOFA score was calculated using the Spearman correlation. $p$ values of the correlations are corrected for multiple testing with Holm-Bonferroni correction. A $p$ value of less than 0.05 was considered statistically significant. Statistical analyses were performed using SPSS ((IBM SPSS Statistics, version 25).

Patient characteristics are shown in Table 1. Median $\mathrm{Hb}$ level at baseline was 6.8 (IQR 6.4-7.3) g/dL and did not correlate with baseline microcirculatory flow (PPV: 
Table 1 Patient characteristics. Data are median with IQR or number with percentage

\begin{tabular}{ll}
\hline & All patients $(n=18)$ \\
\hline Gender, male & $10(56 \%)$ \\
Age (years) & $61[57-66]$ \\
SOFA score & $7[6-11]$ \\
Specialism, surgical & $10(56 \%)$ \\
Sepsis & $7(39 \%)$ \\
Mean arterial pressure $(\mathrm{mmHg})$ & $76[72-82]$ \\
Baseline hemoglobin level $(\mathrm{g} / \mathrm{dL})$ & $6.7[6.4-7.2]$ \\
Vasopressive medication & $6(33.3 \%)$ \\
Lactate (mmol/L) & $1.7[1.2-1.8]$ \\
pH & $7.45[7.42-7.49]$ \\
Arterial saturation & $94.2[93.2-94.8]$ \\
Storage duration RBC unit, days & $16[11-21]$ \\
Hospital mortality & $4[22.2 \%]$ \\
\hline
\end{tabular}

rho $=-0.141, p=0.567$, PVD: rho $=-0.445, p=0.192$, MFI: rho $=-0.276, p=0.534)$. In line with previous findings, the effect of a transfusion depended on the baseline microcirculatory flow, with patients with impaired baseline values showing an improvement and patients with normal baseline values showing a deterioration (PPV: rho $=-0.772, p=0.000$, PVD: rho $=-0.795, p=0.000$, MFI: rho $=-0.697, p=0.001$ ).

No correlation was found between baseline SDF values and the SOFA score (PPV: rho $=-0.382, p=0.288$; PVD: rho $=-0.089, p=0.726 ;$ MFI: rho $=-0.404, p=0.288$ ) indicating that the severity of illness does not correspond with the flow in the microcirculation before transfusion. However, there was a positive correlation between SOFA score and the change in PPV and MFI

$\square$ High SOFA score $(\geq 8) \quad \square$ Low SOFA score $(<8)$

PPV small vessels pre and post transfusion

Correlation Delta PPV and SOFA
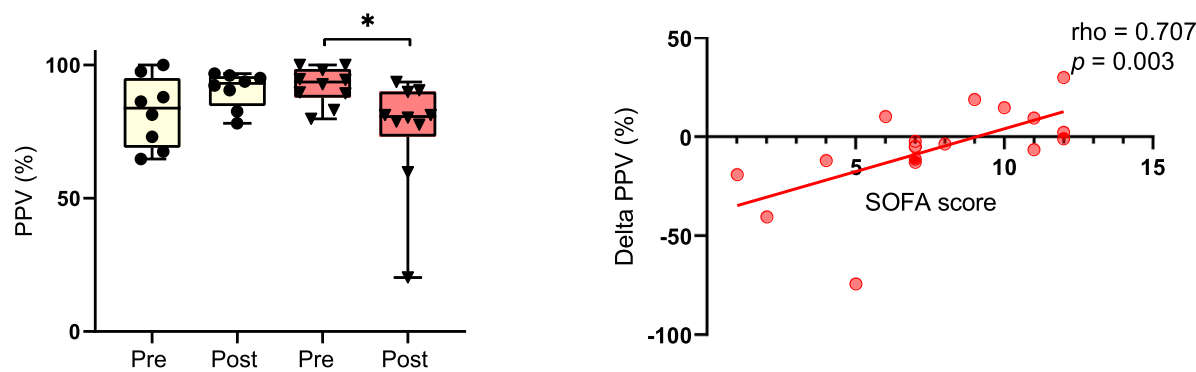

MFI small vessels pre and post transfusion

Correlation Delta MFI and SOFA
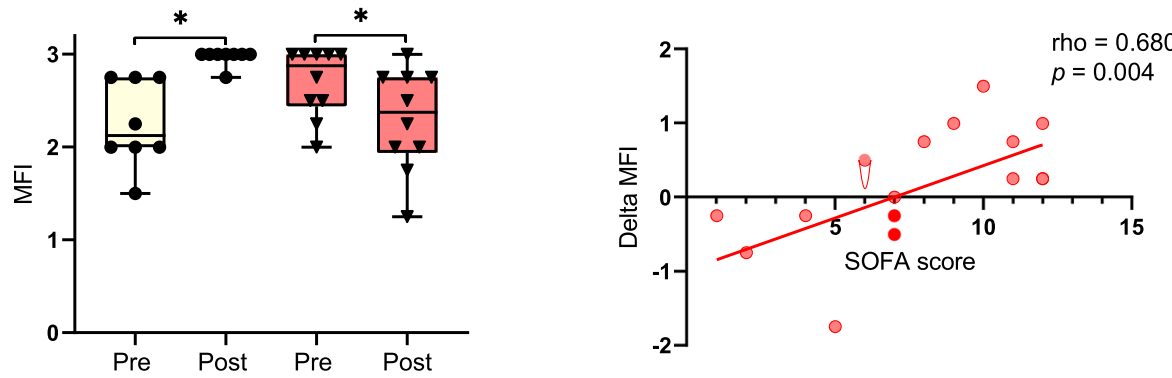

PVD small vessels pre and post transfusion

Correlation Delta PVD and SOFA
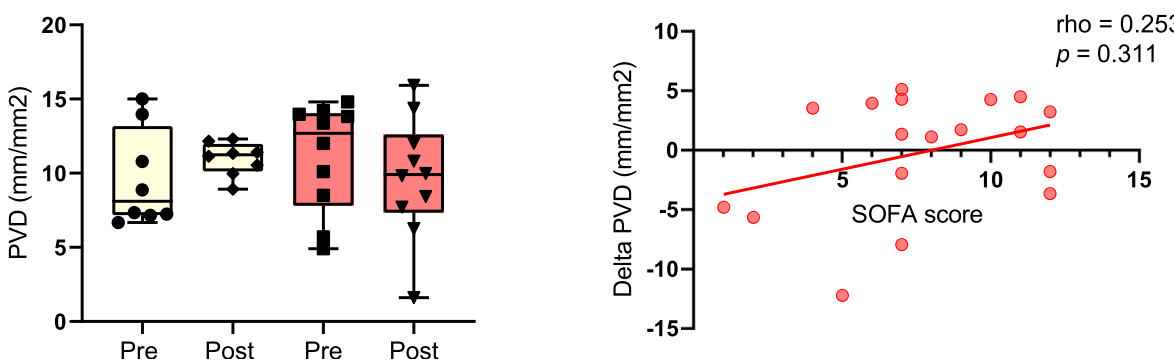

Fig. 1 SDF variables before and after transfusion and correlations between Delta SDF (small vessels) and SOFA score. Pre, before transfusion; post, after transfusion; PPV, proportion of perfused vessels; MFI, microvascular flow index; PVD, perfused vessel density. Rho is Spearman's rank correlation coefficient. ${ }^{*} P \leq 0.05$ 
values after transfusion, in which the microcirculation improved in the patients with a SOFA score $>8$ but deteriorated in those with lower SOFA scores. PVD did not correlate with the SOFA score (Fig. 1).

In conclusion, these results suggest that patients with high SOFA scores have improvement of their microcirculation after a RBC transfusion, while patients with a low SOFA score show a decrease in flow and perfusion following a transfusion. This suggests that we should take the severity of the illness of the patient into account when deciding whom to transfuse, when microcirculatory flow analysis is not available.

\section{Abbreviations}

RBC: Red blood cell; Hb: Hemoglobin; SOFA: Sequential organ failure assessment; SDF: Sidestream DarkField imaging; PPV: Proportion of perfused vessels; PVD: Perfused vessel density; MFI: Microvascular Flow Index

\section{Acknowledgements}

Not applicable

\section{Trial registration}

Netherlands Trial Register (NTR), NL6419/NTR6596. Registered on 26 July

2017. Retrospectively registered.

\section{Authors' contributions}

LM gathered and analyzed the data and wrote the manuscript. JD analyzed the data and revised the manuscript. $\mathrm{MH}$ gathered the data and critically revised the manuscript. $M B$ gathered the data and critically revised the manuscript. RB designed the study and critically revised the manuscript. NJ designed the study and critically revised the manuscript. All authors read and approved the final manuscript.

\section{Funding}

The sponsors of this work had no role in this work including the study design; the collection, analysis, and interpretation of data; the writing of the report; or the decision to submit the manuscript for publication. RVB has received a grant by the Dutch Ministry of Health (grand number PPOC-13018)

\section{Availability of data and materials}

The datasets used and/or analyzed during the current study are available from the corresponding author on reasonable request.

\section{Ethics approval and consent to participate}

The study was ethically approved by the medical ethical committee of the Amsterdam University Medical Centre (NTR 6596; NL61833.018.17). Written informed consent was obtained from all participants or their legal representatives.

\section{Consent for publication}

Not applicable

\section{Competing interests}

The authors declare that they have no competing interests.

\section{Author details}

'Department of Intensive Care Medicine and Laboratory of Experimental Intensive Care and Anesthesiology, Amsterdam UMC, location AMC, University of Amsterdam, Meibergdreef 9, 1105 AZ Amsterdam, The Netherlands. ${ }^{2}$ Department of Blood Cell Research, Sanquin research and Landsteiner Laboratory, University of Amsterdam, Amsterdam, The Netherlands. ${ }^{3}$ Department of Intensive Care Medicine, OLVG Hospital, Amsterdam, The Netherlands.
Received: 17 April 2020 Accepted: 26 July 2020

Published online: 12 August 2020

\section{References}

1. Scheuzger J, Zehnder A, Meier V, Yeginsoy D, Flükiger J, Siegemund M. Sublingual microcirculation does not reflect red blood cell transfusion thresholds in the intensive care unit-a prospective observational study in the intensive care unit. Crit Care. 2020;24(1):18 Available from: http://www. ncbi.nlm.nih.gov/pubmed/31952555.

2. Nielsen ND, Martin-Loeches I, Wentowski C. The effects of red blood cell transfusion on tissue oxygenation and the microcirculation in the intensive care unit: a systematic review. Transfus Med Rev. 2017;31(4):205-22 Available from: http://www.ncbi.n/m.nih.gov/pubmed/28800876.

3. De Backer D, Hollenberg S, Boerma C, Goedhart P, Büchele G, OspinaTascon G, et al. How to evaluate the microcirculation: report of a round table conference. Crit Care. 2007;11(5):R101 Available from: http://www.ncbi. nlm.nih.gov/pubmed/17845716.

\section{Publisher's Note}

Springer Nature remains neutral with regard to jurisdictional claims in published maps and institutional affiliations.
Ready to submit your research? Choose BMC and benefit from:
- fast, convenient online submission
- thorough peer review by experienced researchers in your field
- rapid publication on acceptance
- support for research data, including large and complex data types
- gold Open Access which fosters wider collaboration and increased citations
- maximum visibility for your research: over $100 \mathrm{M}$ website views per year
At BMC, research is always in progress.
Learn more biomedcentral.com/submissions 